\title{
TIM Lecture Series: Next-Generation Technology Challenges and Business Opportunities Dave Thomas
}

\author{
"Seeing the future of technology is pretty easy." \\ Seeing the future of the world is another thing. \\ Dave Thomas \\ Founder and Chairman of Bederra Research Labs
}

\begin{abstract}
The third TIM lecture of 2012 was presented by David Thomas, Founder and Chairman of Bederra Research Labs, who shared his visions for the future of technology as well as the challenges and business opportunities it will bring. The event was held at Carleton University in Ottawa, Canada, on April 19, 2012.

The TIM Lecture Series is hosted by the Technology Innovation Management program (TIM; carleton.ca/tim) at Carleton University. The lectures provide a forum to promote the transfer of knowledge from university research to technology company executives and entrepreneurs as well as research and development personnel. Readers are encouraged to share related insights or provide feedback on the presentation or the TIM Lecture Series, including recommendations of future speakers.
\end{abstract}

This report summarizes the presentation and its key messages, including the lessons learned and actions identified by audience members. The slides from his presentation are available here: tinyurl.com/d36vnxa.

\section{Part 1: Future Technology}

In the first part of his presentation, Dave Thomas examined current technology trends and the future direction of technologies such as mobility, cloud computing, "Big Data", NoSQL databases (tinyurl.com/yes8tem), computer languages and development processes, and outsourcing to cyborgs and robots. Particular emphasis was placed on the explosive growth in new technologies that take advantage of the availability of massive computational power, which is a key driver for future technology.

The presentation also focused on the complexity of current and future technology, which is creating both educational and management challenges. We now have many options available to us, but they come with costs, including: complex integration, multiple languages, leg- acy support, etc. Fortunately, a layer of entrepreneurs are building platforms and tools that make it easier for others to build upon this complexity without needing to become entangled within it. These new tools simplify the creation process to the point that even domain experts can use them, which reduces their dependency on developers. Even so, we will require a new set of skills (e.g., social intelligence, new media literacy, trans-disciplinarity, a design mindset, cross-cultural competency) to succeed with the future landscape of technology.

\section{Part 2: Business Implications}

In the second part of his presentation, Dave Thomas discussed the business side of future technology. As a speculator on the "lunatic fringe" of technology, he de- 


\section{TIM Lecture Series: Next-Generation Technology Challenges and Business Opportunities}

\section{Dave Thomas}

scribes himself as a "wildly optimistic downside planner". This means he reaches for the most optimistic outcomes, but plans ahead for how he might fail: "When it happens, I can recognize it as an event to manage and I already know what to do." This approach highlights the speculative nature of next-generation technology; the chances of failure are high, the landscape is unpredictable, but the potential reward is substantial.

Future technology will require new business models, even though the long-established business models will still be relevant in some areas. Dave Thomas predicts that we will see more companies creating short-lived virtual corporations with partners and increasing segregation of highly innovative business units that can be spun off and re-acquired if future options are sufficiently valuable. He also discussed the implications of lower start-up costs, crowdsourcing, and virtual accelerators, which are creating an increasing number of opportunities for entrepreneurs. However, he noted that there is a difference between using existing technology to develop an opportunity and actually innovating by developing new technology through entrepreneurship. Thus, many of today's "technology startups" are really business ventures that just use IT. For the latter companies, it is the business knowledge that is critical, not the technology.

Dave Thomas encouraged the audience to find a problem that someone cares about, develop domain expertise in that area, and listen carefully to customers to fully understand the pain caused by this problem. As an example, he discussed the pain computer users still feel when communicating with machines. With this simple example, he examined several future technologies that could lead to business opportunities on both the input and output sides of human-computer interaction.

In closing, Dave Thomas emphasized that, to make money in next-generation technology, entrepreneurs need to be inventing the technology or at least leading the technology. This can be a demanding and time-consuming process, which takes a minimum of three years just to acquire the necessary knowledge and potentially takes many more years to perfect the technology. However, it is not enough to be in a leadership position with respect to creating value with new technology; constant dialogue with potential customers is also essential to extract value from the technology.

\section{Lessons Learned}

In the discussions that followed the first and second parts of the presentation, audience members shared the lessons learned they learned from the presentation and injected their own knowledge and experience into the conversation.

The audience also identified the following key takeaways from the presentation:

1. Prognosticators are unable to see 20 to 40 years into the future in the way they used to (e.g., science fiction writers). It is becoming harder to anticipate new technologies.

2. The future will require more generalized knowledge than specialized knowledge.

3. Nowadays, all computation is really a query.

4. Develop solutions that are "fit to task" - they do not need to be perfect.

5. Many technologies are really just different embodiments of past technologies.

6. You need to fail fast to learn and improve. There is great value in learning early on that a customer does not see the value in your product.

7. If you never leave your discipline, you can never solve the big problems.

8. Learn to live in "problem space" and "customer space".

9. Hide the complexity - just give the end user a simple tool that lets them solve their problem.

10. Pain is a source of opportunity.

11. Domain expertise is a valuable form of intellectual property.

12. What is the difference between an entrepreneur and a founder? The entrepreneur can sell!

13. If you cannot convince anyone that your idea has value, you should not bother building it. 


\section{TIM Lecture Series: Next-Generation Technology Challenges and Business Opportunities}

\section{Dave Thomas}

14. Ideas are plentiful, but the real value comes from execution. Only in very rare cases can ideas be sold.

15. You need to do more than think outside the box; you need to think beyond the box.

16. Choose something that is not obvious. Many will think you are wrong. You should ignore them if you can validate your idea with a few important customers.

\section{Suggested Next Steps}

To conclude the evening, the host - Dr. Tony Bailetti, Director of the TIM program - challenged the audience to identify community actions that could be taken to establish a leadership position in entrepreneurship and next-generation technology:

1. Increase the emphasis on sales and marketing among entrepreneurs in our community, including the need to "sell ideas" in terms of testing concepts with customers.

2. Renew the branding of our region. The old brand was "Silicon North" - the time for renewal is now.

3. Encourage engineers to understand the value of "business people". This is often a weakness in a technical community.

4. Encourage interdisciplinary collaboration. This is essential if we are to exploit future technologies and business opportunities.

5. Create focused, high-value networking groups, not just groups for job seekers or service providers.

6. Hold more events with top speakers: ones that are widely recognized as experts, who know what they are talking about, and communicate effectively.

\section{About the Author}

Dave Thomas has a wide spectrum of experience in the software industry as an engineer, consultant, architect, executive and investor (davethomas.net). $\mathrm{He}$ is the Founder and Chairman of Bedarra Research Labs (bedarra.com), a company specializing in emerging software technologies and applications. Bedarra provides virtual CTO and CEO, as well as directors, advisers, and business mentors to support new initiatives. He is also the Managing Director of Object Mentor (objectmentor.com), a company specializing in the training and deployment of agile and object-oriented software development methodologies. Dave is best known as the founder and past CEO of Object Technology International Inc. (formerly OTI, now IBM OTI Labs), where he led the commercial introduction of object and component technology. The company is often cited as the ideal model of a software technology company and was a pioneer in agile product development with a process called "just-in-time software".

Citation: Thomas, D. 2012. TIM Lecture Series: NextGeneration Technology Challenges and Business Opportunities. Technology Innovation Management Review. May 2012: 35-37. 